\title{
Tooth Wear in Patients Submitted to Bariatric Surgery
}

\author{
Maria do Socorro Coêlho ALVES ${ }^{1}$ \\ Fernando Alberto Costa Cardoso da SILVA ${ }^{2}$ \\ Stephanie Gomes ARAÚJO ${ }^{1}$ \\ Antônio Cláudio Almeida de CARVALHO ${ }^{3}$ \\ Alcione Miranda SANTOS 4 \\ Andrea Lúcia Almeida de CARVALHO \\ ${ }^{1}$ Dental School, UFMA - Federal University of Maranhão, São Luiz, MA, Brazil \\ ${ }^{2}$ University Hospital, UFMA - Federal University of Maranhão, São Luís, MA, Brazil \\ ${ }^{3}$ Brazilian Agricultural Research Agency, Macapá, AP, Brazil \\ ${ }^{4}$ Department of Public Health, UFMA - Federal University of Maranhão, São Luiz, MA, Brazil \\ ${ }^{5}$ Department of Dentistry, Dental School, UFMA - Federal University of Maranhão, São Luiz, MA, Brazil
}

\begin{abstract}
Bariatric surgery may cause frequent vomiting episodes and gastroesophageal reflux, which promote the contact of gastric acids with the teeth leading to irreversible loss of tooth structure. The aim of this study was to assess prevalence of tooth wear in bariatric patients. One hundred and twenty-five patients were examined at a Public Hospital in São Luis, MA, Brazil, between July and October 2010, being patients who had already been submitted to the bariatric surgery at least 6 months previously (Bariatric group), morbidly obese patients who were on the waiting list for this surgery (Obese group) and patients who were waiting for ambulatory medical care in other sectors (Control group). The patients answered an investigative questionnaire and were clinically examined using the Basic Erosive Wear Examination (BEWE) scoring system, which allows the classification of the severity of noncarious dental lesions (NCDL) and evaluation of risk. All patients presented some degree of tooth wear at different levels. However, the presence of NCDL was associated with the group to which the patient belonged. The bariatric patients showed higher prevalence and a statistically significant level of risk with regard to NCDLs when compared with the other patients, followed by the obese and control groups. Reflux and vomiting did not seem to influence NCDL positively.
\end{abstract}

Key Words: Bariatric surgery, tooth wear, oral health.

\section{INTRODUCTION}

Bariatric surgery is currently the only effective treatment for morbidly obese patients as it achieves significant and sustained weight loss for millions of individuals who suffer from morbid obesity. The present popular operative procedures are all relatively safe and efficient. However, all these procedures alter anatomy and physiology of the gastrointestinal tract to variable degrees (1). Therefore, surgery is not the final step of obesity treatment, but it is rather the beginning of a 1-2-year period of changes in behavior, diet and physical activity followed by regular follow-up of a multidisciplinary team of health professionals (2). The alterations in the gastrointestinal shape and function associated with the postoperative dietary changes make these patients vulnerable to a series of potential complications, such as abdominal pain, gallbladder disease (biliary calculi), intestinal obstruction, peptic ulcer, gastroesophageal reflux, nausea and vomiting episodes $(1,2)$.

The gastroesophageal reflux disease (GERD), a condition of high and rising incidence, may manifest itself by typical (pyrosis and regurgitation) and atypical (pulmonary, otorhinolaryngological and oral problems) symptoms. Patients with GERD present a higher incidence of dental erosion, aphthas, burning mouth sensation, tooth sensitivity and a sour taste in 
the mouth $(3,4)$.

Studies relate eating disorders (bulimia) to episodes of vomiting, oral cavity implications, among them, tooth wear $(5,6)$.

The etiology of tooth wear is multifactorial and it may result in the 3 following processes: abrasion (wear caused by the interaction between teeth and other materials), attrition (wear caused by tooth-totooth contact) and erosion (dissolution of dental hard tissues due to acid substances). An additional process (abfraction) may accentuate wear by abrasion and/or erosion. Clinical and experimental observations show that individual tooth wear rarely occurs alone, but they interact one with the other. This interaction seems to be the main factor for tooth wear (7). Due to the nature of this phenomenon, these lesions may lead to significant oral health consequences. Dental tissue loss may result in sensitivity, pulp necrosis, pain, loss of vertical dimension and an unpleasant appearance (8).

Data referring to the oral health condition and gastric reduction surgery are still scarce. A study in Jerusalem with 113 patients found high tooth sensitivity after bariatric surgery (9).

Since bariatric surgery can cause frequent episodes of gastroesophageal reflux and vomiting, promoting contact of the teeth with gastric acids, an investigation was considered necessary. The aim of this study was to determine prevalence of tooth wear as well as the level of risk in a sample of bariatric patients from a Brazilian public hospital.

\section{MATERIAL AND METHODS}

A sample selected from the University Hospital of Federal University of Maranhão (UH-FUMA), located in the city of São Luís, MA, Brazil, participated in this cross-sectioned epidemiological study. The participants were divided into 3 groups: the Bariatric group was composed of patients who had been submitted to bariatric surgery at least 6 months previously; the Obese group was composed of patients on the waiting list for this surgery; the Control group was composed of patients from other sectors of the same hospital who were waiting for an ambulatory medical care. All patients who agreed to participate signed an informed consent form and the research protocol was approved by the Ethics Committee of the above-mentioned hospital (report \#149/2010), in accordance with resolution 196/96 of the Brazilian National Health Council.
One hundred and thirty-nine patients accepted to participate in the study. Fourteen patients who did not meet the inclusion criteria were excluded from the research. The exclusion criteria were as follows: patients with debilitating systemic conditions and active periodontal disease, seniors over the age of 70 , children and pregnant women; patients who underwent selective wear and dental bleaching; complete denture wearers, and individuals with removable orthodontic appliances. Patients included in the study were between the ages of 16 and 70 , totaling 125 participants.

Before collecting the clinical data, the examiner was trained and intra-examiner agreement was verified by the Kappa index. For this step of the study, 20 patients were examined at two distinct time periods with an interval of 15 days, reaching the Kappa value of 0.9 which is considered excellent since this value is greater than 0.85 .

The data collection instruments were the dental examination and the investigative questionnaire.

\section{Clinical Examination}

All teeth between the second molars, including these, were examined in both dental arches for the presence or absence of noncarious lesions.

A recently proposed tooth wear index for classification of the severity of tooth wear or tooth erosion in studies of prevalence and incidence was used. This index, called Basic Erosive Wear Examination (BEWE) was designed to provide a simple and reproducible scoring system (10), appropriate for screening. The four- level score (Table 1) grades the appearance or severity of wear on the teeth from no surface loss (0), initial loss of enamel surface texture (1), distinct defect, hard tissue loss (dentin) less than $50 \%$ of the surface area (2) or hard tissue loss more than $50 \%$ of the surface area (3). Buccal, occlusal, lingual and palatal surfaces of all teeth in each sextant were examined, but only the score of the tooth surface that showed the highest value was recorded (10).

From the scores obtained in each sextant, the cumulative sum was performed and therefore, a total score of the level of risk for tooth wear of each patient was obtained. Risk is understood as the probability of the occurrence of an unfavorable event. No risk (below or equal to 2), low risk (between 3 and 8), medium risk (9 to 13 ) and high risk (14 or above) (Table 2).

The the term noncarious dental lesions (NCDL) 
was used to indicate the prevalence of tooth wear.

\section{Specific Questionnaire}

In the investigative questionnaire, the sociodemographic data of the patient (name, age, sex, education, occupation, income, color/race selfdesignation) and data collection of the patient's family income based on the income of minimum wages of those responsible for providing for the family were obtained. Therefore, the patients selected the correspondeing monthly income, based on the value of the present minimum wage ( $\mathrm{R} \$ 510,00)$, from the following options: up to 1 minimum wage; from 1 to 2 minimum wages, from 2 to 3 ; from 3 to 5 ; from 5 to 10 ; and above 10 . Information on the systemic conditions, such as selfreported gastroesophageal reflux and vomiting episodes, were also collected.

The collected data were entered and analyzed in STATA 10.0 (Stata Corp LP, College Station, TX, USA). There has been a descriptive analysis by means of absolute and relative frequencies. Chi-Square and Fisher's Exact test was used to compare the study groups with respect to some qualitative variables. A significance level of 5\% was considered for all analyses.

Table 1. Criteria for classifying tooth wear or dental erosion according to the Basic Erosive Wear Examination scoring system.

\begin{tabular}{lc}
\hline Score & Criteria for wear classification \\
\hline 0 & No loss of surface \\
1 & Initial loss of surface texture \\
2 & $\begin{array}{c}\text { Distinct defect, hard tissue loss } \\
<50 \% \text { of the surface area }\end{array}$ \\
3 & Hard tissue loss $\geq 50 \%$ of the surface area \\
\hline
\end{tabular}

Score 1: slight wear; Scores 2 and 3: Dentin is frequently involved (noncarious dental lesions), representing moderate and severe lesions, respectively. Source: Adapted from Bartlett et al. (2008).

Table 2. Calculation of total score and risk level based on the Basic Erosive Wear Examination scoring system.

\begin{tabular}{lcccccccc}
\hline Sextant & 1 & 2 & 3 & 4 & 5 & 6 & Total & Risk \\
& $(17-14)$ & $(13-23)$ & $(24-27)$ & $(37-34)$ & $(33-43)$ & $(44-47)$ & score & level \\
\hline $\begin{array}{l}\text { Higher } \\
\text { value }\end{array}$ & & & & & & & & \\
\hline
\end{tabular}

Source: Adapted from Bartlett et al. (2008).

\section{RESULTS}

\section{Sample Characterization}

A total of 125 individuals were assessed, of which $41(32.80 \%)$ were bariatric patients, $42(33.60 \%)$ were morbidly obese patients and 42 (33.60\%) were control patients. The socio-demographic characteristics of the sample are summarized in Table 3. Regarding the number of individuals assessed per group, the variables sex, smoking, educational level (years) and ethnicity showed homogeneous proportions with no statistically significant differences among the groups $(p>0.05)$. The proportion of women was higher in the 3 groups. However, the groups differed significantly with respect to economic classification and mean age $(p<0.05)$.

\section{NCDL Evaluation per Patient}

All patients presented some degree of tooth wear at different levels. However, the presence of NCDL was associated with the group to which the patient belonged. The Bariatric group showed the highest prevalence of NCDL (97.56\%). This result was similar when the Bariatric group was compared with the Obese group (40 patients or $97.56 \% v s .35$ patients or $83.33 \%, \mathrm{p}=0.031$ ) and with the Control group (40 patients or $97.56 \%$ vs. 26 patients or $61.90 \%, \mathrm{p}<0.001)$. A higher frequency of NCDL was also found when the Obese group was compared with the Control group (35 patients or $83.33 \%$ vs. 26 patients or $61.90 \%, \mathrm{p}=0.024$ ) (Fig. 1).

\section{Risk Level of NCDL per Patient}

The highest percentage of patients with no risk was found in the Control group (23.82\%) followed by the Obese group (7.14\%). In the Bariatric group, all patients presented some level of risk. However, when the Bariatric group was compared with the Obese group $(0.00 \%$ vs. $7.14 \%, \mathrm{p}=0.125)$, no significant difference was found. The highest proportion of low risk was found in the Control group $(64.28 \%)$ with a significant difference from the Bariatric group ( $\mathrm{p}=0.002)$. When the Obese and Bariatric groups $(61.91 \%$ vs. $31.71 \%, \mathrm{p}=0.003$ ) were compared, the Obese group showed a higher proportion of NCDL, but such a 
difference was not found between the Control and Obese groups (Table 4).

The Bariatric group showed the highest percentage of medium risk (63.41\%). A statistically significant difference was found between the Bariatric and Obese group $(63.41 \%$ vs. $30.95 \%, \mathrm{p}=0.003)$ and between the Bariatric and Control group (63.41\% vs. $11.90 \%$, $\mathrm{p}<0.001)$. A high level of risk was found in the Bariatric group (4.88\%), though not statistically significant.

\section{Reflux and Vomiting}

With regard to the self-reported gastroesophageal reflux, the Bariatric group obtained the highest statistically significant occurrence when compared with the Obese group $(63.41 \%$ vs. $28.57 \%, \mathrm{p}=0.001)$ and Control group (63.41\% vs. $2.38 \%, \mathrm{p}<0.001)$; whereas in the Obese group, a significantly higher percentage was found in comparison with Control group $(28.57 \%$ vs. 2.38 $\%, \mathrm{p}=0.001)$. Regarding self-reported vomiting episodes, the Bariatric group showed a higher percentage than the Obese group (60.98\% vs. $14.28 \%, \mathrm{p}<0.001)$ and Control group (60.98\% vs. $2.38 \%, \mathrm{p}<0.001)$; when comparing the obese and Control groups ( $14.28 \%$ vs. $2.38 \%, \mathrm{p}=0.048)$, a statistically significant higher percentage was found in the Obese group (Table 5).

Table 3. Frequency of the socio-demographic characteristics of 125 patients of the UH- FUMA.

\begin{tabular}{|c|c|c|c|c|c|c|c|}
\hline \multirow{2}{*}{ Variables } & \multicolumn{2}{|c|}{ Bariatric $(n=41)$} & \multicolumn{2}{|c|}{ Obese $(n=42)$} & \multicolumn{2}{|c|}{ Control $(n=42)$} & \multirow{2}{*}{$\mathrm{p}$-value } \\
\hline & $\mathrm{n}$ & $\%$ & $\mathrm{n}$ & $\%$ & $\mathrm{n}$ & $\%$ & \\
\hline Gender & & & & & & & 0.359 \\
\hline Women & 38 & 92.68 & 35 & 83.33 & 35 & 83.33 & \\
\hline Men & 3 & 7.32 & 7 & 16.67 & 7 & 16.67 & \\
\hline Age (years) & & & & & & & $<0.001^{*}$ \\
\hline Mean (S.D.) & \multicolumn{2}{|c|}{$42.707(9.450)$} & \multicolumn{2}{|c|}{$36.523(10.177)$} & \multicolumn{2}{|c|}{$33.380(9.985)$} & \\
\hline Smoke & & & & & & & 0.402 \\
\hline No & 39 & 95.12 & 41 & 97.62 & 38 & 90.48 & \\
\hline Yes & 2 & 4.87 & 1 & 2.38 & 4 & 9.52 & \\
\hline $\begin{array}{l}\text { (CCEB) Economic } \\
\text { classification }\end{array}$ & & & & & & & $0.020^{*}$ \\
\hline Class A & 13 & 31.71 & 8 & 19.05 & 11 & 26.19 & \\
\hline Class B & 20 & 48.78 & 14 & 33.33 & 10 & 23.81 & \\
\hline Class C, D and E & 8 & 19.51 & 20 & 47.62 & 21 & 50 & \\
\hline Educational level (years) & & & & & & & 0.069 \\
\hline$\leq 4$ & 2 & 4.88 & 4 & 9.52 & 3 & 7.14 & \\
\hline $4-9$ & 4 & 9.76 & 11 & 26.19 & 14 & 33.33 & \\
\hline$\geq 10$ & 35 & 85.36 & 27 & 64.28 & 25 & 59.52 & \\
\hline Skin Color & & & & & & & 0.756 \\
\hline White & 13 & 31.71 & 12 & 28.57 & 10 & 23.81 & \\
\hline Black & 5 & 12.20 & 5 & 11.90 & 7 & 16.67 & \\
\hline Mulatto & 20 & 48.78 & 24 & 57.14 & 22 & 52.38 & \\
\hline Yellow & 2 & 4.88 & 0 & 0 & 3 & 7.14 & \\
\hline Indigenous & 1 & 2.44 & 1 & 2.38 & 0 & 0 & \\
\hline
\end{tabular}

Symbol indicates statistically significant differences (Chi-square and Fisher's exact tests, $\mathrm{p}<0.05$ ). 
The Bariatric group differed significantly from the other groups and had the highest prevalence of NCDL, reflux and vomiting. However, reflux and vomiting did not seem to influence NCDL positively ( $p>0.05$ ).

\section{DISCUSSION}

There is currently an increasing interest in

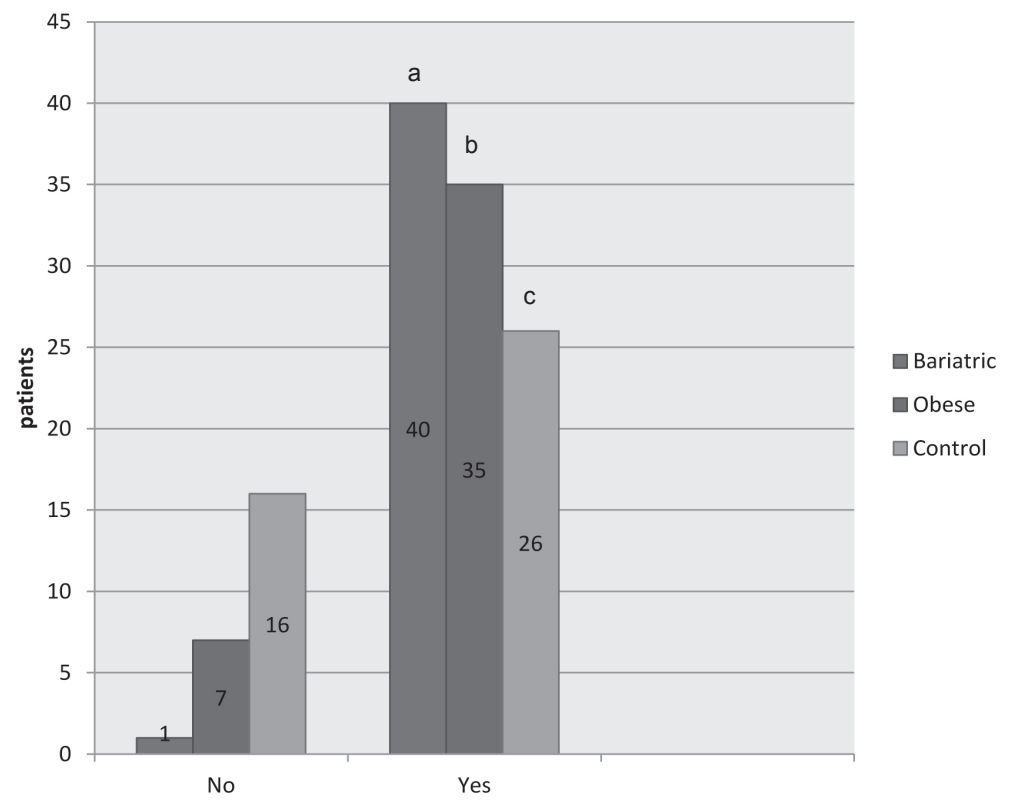

Figure 1. Prevalence of noncarious dental lesions in the bariatric, obese and control patients of the UH-FUMA. NCDL. Yes - (score $2+$ score 3$)$, that is, pathological wear. No - (score 1), physiological wear. Different letters indicate statistically significant differences (Chi-square and Fisher's exact tests, $\mathrm{p}<0.05$ ).
NCDL. Epidemiological studies have shown results for prevalence ranging from $5 \%$ to $85 \%$, irrespective of the type and etiology of these lesions $(7,11,12)$. Differences in the prevalence data among the studies may be explained due to the different diagnostic criteria and indexes used (10). In this study, the BEWE scoring system was used, which was suitable for epidemiological and clinical trials because it has fewer categories and therefore, it is easier to memorize, enabling good examiner training (Kappa $=0.9)$, as reported elsewhere (12).

There has not yet been evidence that income contributes to the appearance of NCDL, for studies have shown contradictory results. It is understood that low income influences educational level, oral hygiene and diet habits and that a higher educational level provides more knowledge about general health and oral care (13). However, tooth wear has been found to be prevalent in children whose families have a higher income when compared with families who have a lower income (14). In the sample of this research, a difference in the 3 groups with regard to monthly income was found, but the educational level showed a homogeneous proportion (most had high school education). The Bariatric group, had the highest monthly income (most patients from classes $\mathrm{A}$ and $\mathrm{B}$ ), but also
Table 4. Distribution of level of risk of NCDL in bariatric, obese and control patients.

\begin{tabular}{|c|c|c|c|}
\hline \multirow{2}{*}{$\begin{array}{l}\text { Level } \\
\text { of risk }\end{array}$} & Bariatric & Obese & Control \\
\hline & $\%$ & $\%$ & $\%$ \\
\hline
\end{tabular}

\begin{tabular}{lcccccc} 
None & 0 & $0^{\mathrm{b}}$ & 3 & $7.14^{\mathrm{b}}$ & 10 & $23.82^{\mathrm{a}}$ \\
Low & 13 & $31.71^{\mathrm{b}}$ & 26 & $61.91^{\mathrm{a}}$ & 27 & $64.28^{\mathrm{a}}$ \\
Medium & 26 & $63.41^{\mathrm{a}}$ & 13 & $30.95^{\mathrm{b}}$ & 5 & $11.90^{\mathrm{c}}$ \\
High & 2 & $4.88^{\mathrm{a}}$ & 0 & $0^{\mathrm{a}}$ & 0 & $0^{\mathrm{a}}$ \\
& & & & & & \\
Total & 41 & 100 & 42 & 100 & 42 & 100 \\
\hline
\end{tabular}

Different letters in the same line indicate statistically significant differences (Chi-square and Fisher's Exact tests, $\mathrm{p}<0.05$ ).
Table 5. Distribution of the presence of gastroesophageal reflux and vomiting in bariatric, obese and control patients.

\begin{tabular}{|c|c|c|c|c|c|c|}
\hline \multirow{2}{*}{ Variable } & \multicolumn{2}{|c|}{ Bariatric (41) } & \multicolumn{2}{|c|}{ Obese (42) } & \multicolumn{2}{|c|}{ Control (42) } \\
\hline & $\mathrm{n}$ & $\%$ & $\mathrm{n}$ & $\%$ & $\mathrm{n}$ & $\%$ \\
\hline
\end{tabular}

GERD

\begin{tabular}{ccccccc} 
Yes & 26 & $63.41^{\mathrm{a}}$ & 12 & $28.57^{\mathrm{b}}$ & 01 & $2.38^{\mathrm{c}}$ \\
No & 15 & 36.58 & 30 & 71.43 & 41 & 97.62 \\
Vomiting & & & & & & \\
Yes & 25 & $60.98^{\mathrm{a}}$ & 06 & $14.28^{\mathrm{b}}$ & 01 & $2.38^{\mathrm{c}}$ \\
No & 16 & 39.02 & 36 & 85.71 & 41 & 97.62 \\
\hline
\end{tabular}

GERD: Gastroesophageal reflux disease. Different letters in rows indicate statistically significant differences (Chi-square and Fisher's Exact tests, $\mathrm{p}<0.05)$. 
showed the highest prevalence of NCDL.

The pathogenesis of tooth wear was discussed throughout the past century and there are still controversy and incoherences. Human teeth are subjected to constant physiological wear during the individual's entire life and this phenomenon is probably related to age (15). Thus, in this study, the presence of enamel wear was also common to all volunteers, which is in agreement with the above-mentioned research (16). However, severe degrees of wear were observed in different age groups, which could be caused irrespective of age (15) and may even lead to complete destruction of teeth (8).

The highest prevalence of NCDL (score 2 and score 3 ) found in this research occurred in the Bariatric group with a percentage of $97.56 \%$, a higher frequency than the one found in the literature. It is believed that this high prevalence was due to the sample being composed of individuals who could have been more exposed to agents that cause these lesions. Another result that is a matter of concern refers to the Obese group in which $83.33 \%$ of patients presented moderate and severe dental lesions, leading to the assumption that it is believed that NCDL in morbidly obese patients may progress to higher levels if there is no intervention, as those observed in patients who have undergone bariatric surgery. The development of NCDL is a gradual and variable process that requires analysis of each case in particular to prepare a treatment plan and provide guidance on the patient's diet and habits. Prevention would be the most efficient and relevant manner to prevent the appearance of lesions as well as their progression when it is already existent and prevention is indicated for the general population. However, some authors (10) recommend that dentists who have patients with high and medium risk, as well as bariatric patients, in addition to the procedures described previously, should identify the etiology of wear, use fluoride to increase resistance of the tooth surface, monitor study models, photographs and clinical examinations in a time interval of 6 to 12 months, to evaluate, in special cases of severe progression, the need for restoring the teeth.

At present, lifestyle creates nutritional conditions that are potentially dangerous for oral health. Patients, who have undergone gastric reduction surgery and do not adapt themselves to the new dietary habits, may present gastroesophageal disturbances. It was found that the highest frequency of reflux and vomiting episodes (63.41\% and $60.98 \%$, respectively) occurred in the Bariatric group. However, irrespective of the group
(Bariatric, Obese and Control), no association between reflux, vomiting and NCDL was found in this study. This result was also found for patients with reflux (17). Contrary to these findings, other studies $(4,6)$ observed association between reflux, vomiting and NCDL in the general population. This difference in results may be related not to the difference, but to the frequency of reflux and vomiting in each patient, which was not investigated in the present study. Other factors have been investigated and a significant correlation between NCDL and toothbrushing more than once a day with a medium or hard toothbrush, vegetarian diets and self-reported intake of citrus fruit, sodas, vinegar used in spices, alcohol, yoghurt, vitamin $\mathrm{C}$ and carbonated beverages $(18,19)$ were found. Most authors agree that the cause is multifactorial and it is difficult to attribute a primary etiological factor. Therefore, a cumulative effect probably occurs from many etiological factors $(7,11,15,18,20)$.

This is the first study that has assessed prevalence of tooth wear in bariatric, obese and control patients in Brazil concomitantly and a high, medium and low prevalence was found, respectively. These frequent occurrences should not be ignored and they have become a public health problem, as NCDL are not only an esthetic problem, but a functional problem with the possibility of causing dental loss. Therefore, health teams need to consider potential dental problems after this surgery and provide their patients with information and appropriate instructions, in addition to regular monitoring of teeth by a dentist. The oral health is inseparable from the overall health of the individual, dental care is essential and necessary to improve the quality of life.

The following factors were a limitation of the research, as they were not considered in the present study: diet, oral hygiene, periodontal and occlusion condition, habits such as bruxism, and quality and quantity of saliva, which may contribute to tooth wear. The clinical criteria of the BEWE could be accompanied by a group of dietary, behavioral and biological criteria (21). In addition, this study only analyzed the number of non-restored lesions and consequently, the data do not represent the number of lesions since they could have been restored or teeth could have been extracted. However, the results of this study show the importance of a preventive approach of the most susceptible groups, as in the case of bariatric patients, as these lesions could have been avoided through continuous control. Furthermore, it was found that the Obese group was second in prevalence, 
being higher than in the Control group. This is equally important since obesity is a major public health problem affecting millions of people worldwide. As this was preliminary investigation, further studies are needed, especially prospective studies.

In conclusion, the bariatric patients showed the highest prevalence and level of risk with regard to NCDL when compared with the morbidly obese and control patients. However, reflux and vomiting did not seem to influence the appearance of NCDL positively.

\section{RESUMO}

Cirurgia bariátrica pode provocar freqüentes episódios de vômito e refluxo gastroesofágico o que promove o contato dos ácidos gástricos com os dentes fazendo que haja perda irreversível de estrutura dental. Este estudo teve como objetivo avaliar a prevalência de desgaste dentário em pacientes bariátricos. Foram examinados 125 pacientes em um Hospital Público de São Luís, MA no período de julho a outubro de 2010, distribuídos em pacientes que já tinham sidos submetidos à cirurgia bariátrica há pelo menos 6 meses (Grupo bariátrico), obesos mórbidos que estavam na lista de espera para esta cirurgia (Grupo obeso) e por pacientes que esperavam por consulta médica ambulatorial em outros setores (Grupo controle). Os pacientes responderam a um questionário investigativo e foram examinados clinicamente utilizando o "Basic Erosive Wear Examination" - BEWE (Índice Básico do Desgaste Erosivo) que permite a classificação da severidade das lesões não-cariosas e avaliação de risco. Todos os pacientes apresentaram algum grau de desgaste dentário em diferentes níveis. No entanto, a presença de LDNC (lesão dental não-cariosa) estava associada ao grupo que o paciente pertencia. O grupo bariátrico apresentou maior prevalência e nível de risco em relação às LDNC's estatisticamente significante quando comparado aos outros grupos, seguido pelo grupo de obeso e controle. Refluxo e vômito parecem não influenciar positivamente nas LDNC.

\section{REFERENCES}

1. Shikora SA, Kim JJ, Tarnoff ME. Nutrition and gastrointestinal complications of bariatric surgery. Nutr Clin Pract 2007;22:29-40.

2. Breznikar B, Dinevski D. Bariatric surgery for morbid obesity: pre-operative assessment, surgical techniques and post-operative monitoring. J Int Med Res 2009;37:1632-1645.

3. Corrêa MCCSF, Lerco MM, Henry MACA. Study in oral cavity alterations in patients with gastroesophageal reflux disease. Arq Gastroenterol 2008;45:132-136.

4. Moazzez, R, Bartlett D, Anggiansah A. Dental erosion, gastrooesofageal reflux disease and saliva: how are they related? J Dent 2004;32:489-494.
5. Aranha AC, Eduardo Cde P, Cordás TA. Eating disorders part II: clinical strategies for dental treatment. J Contemp Dent Pract 2008;9:89-96.

6. Emodi-Perlman A, Yoffe T, Rosenberg N, Eli I, Alter Z, Winocur E. Prevalence of psychologic, dental, and temporomandibular signs and symptoms among chronic eating disorders patients: a comparative control study. J Orofac Pain 2008;22:201-208.

7. Addy M, Shellis RP. Interaction between attrition, abrasion and erosion in tooth wear. Monogr BucalSci 2006;20:17-31.

8. Yip KH, Smales RJ, Kaidonis JA. Differential wear of teeth and restorative materials: clinical implications. Int J Prosthodont 2004; 17:350-356.

9. Heling I, Sgan-Cohen HD, Itzhaki M, Beglaibter N, Avrutis O, Gimmon Z. Dental complications following gastric restrictive bariatric surgery. Obes Surg 2006;16:1131-1134.

10. Bartlett D, Ganss C, Lussi A. Basic Erosive Wear Examination (BEWE): a new scoring system for scientific and clinical needs. Clin BucalInvest 2008; 12:S65-S68.

11. Levitch LC, Bader JD, Shugars DA, Heymann HO. Non-carious cervical lesions. J Dent 1994;22:195-207.

12. Mulic A, Tveit AB, Wang NJ, Hove LH, Espelid I, Skaare AB. Reliability of two clinical scoring systems for dental erosive wear. Caries Res 2010;44:294-299.

13. Al-Dlaigan YH, Shaw L, Smith A. Dental erosion in a group of British 14-year-old school children. Part I: prevalence and influence of differing socioeconomic backgrounds. Br Dent J 2001;190:145-149.

14. Mangueira DF, Sampaio FC, Oliveira AF. Association between socioeconomic factors and dental erosion in Brazilian schoolchildren. J Public Health Dent 2009;69:254-259.

15. Bartlett D, Dugmore C. Pathological or physiological erosion - is there a relationship to age? Clin Oral Invest 2008;12:S27-S31.

16. Fares J, Shirodaria S, Chiu K, Ahmad N, Sherriff M, Bartlett D. A new index of tooth wear. Reproducibility and application to a sample of 18-to 30-year-old university students. Caries Res 2009;43:119-125.

17. Di Fede O. Oral manifestations in patients with gastro-esophageal reflux disease: a single-center case-control study. J Oral Pathol Med 2008;37:336-340.

18. Smith WA, Marchan S, Rafeek RN.The prevalence and severity of non-carious cervical lesions in a group of patients attending a university hospital in Trinidad. J Oral Rehabil 2008;35:128-134.

19. Torres CP, Chinelatti MA, Gomes-Silva JM, Rizóli FA, Oliveira MA, Palma-Dibb RG, et al.. Surface and subsurface erosion of primary enamel by acid beverages over time. Braz Dent $\mathrm{J}$ 2010;21:337-345.

20. El Aidi H, Bronkhorst EM, Huysmans MC, Truin GJ. Multifactorial analysis of factors associated with the incidence and progression of erosive tooth wear. Caries Res 2011;45:303-312.

21. Margaritis V, Mamai-Homata E, Koletsi-Kounari H, Polychronopoulou A. Evaluation of three different scoring systems for dental erosion: a comparative study in adolescents. J Dent 2011;39:88-93.
Received June 16, 2011

Accepted November 17, 2011 